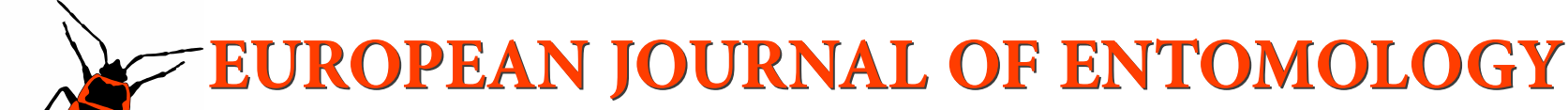 ISSN (online): 1802-8829 \\ http://www.eje.cz \\ Eur. J. Entomol. 118: 82-89, 2021 \\ doi: 10.14411/eje.2021.010 \\ ORIGINAL ARTICLE
}

\section{Laboratory rearing of Abidama liuensis (Hemiptera: Cercopidae) and description of immature stages}

\author{
QIQI WANG ${ }^{1,2}$, LINGYAN BAI ${ }^{1,2}, X_{U}$ CHEN $^{1,3}$ and AIPING LIANG ${ }^{1,2,3, *}$ \\ ${ }^{1}$ Key Laboratory of Zoological Systematics and Evolution, Institute of Zoology, Chinese Academy of Sciences, 1 Beichen \\ West Road, Chaoyang District, Beijing 100101, P.R. China; e-mails: 763552719@qq.com, bailingyan0322@163.com, \\ cxeastsun@163.com, liangap@ioz.ac.cn \\ ${ }^{2}$ College of Life Sciences, University of Chinese Academy of Sciences, 100049 Beijing, China \\ ${ }^{3}$ Tianjin Key Laboratory of Conservation and Utilization of Animal Diversity, Tianjin Key Laboratory of Animal and Plant \\ Resistance, College of Life Sciences, Tianjin Normal University, 393 Binshuixidao Road, Xiqing District, Tianjin 300387, China \\ ORCiD. Qiqi Wang: 0000-0003-0245-595X; Aiping Liang: 0000-0001-6249-1704.
}

Key words. Hemiptera, Cercopidae, Abidama liuensis, spittlebug, laboratory rearing, egg, immature stages

\begin{abstract}
Because it is an important pest of rice, Abidama liuensis Metcalf is well documented in terms of its bioecology and control. However, there are few studies on the biology of this pest. In this study, a technique was developed for rearing this insect under laboratory conditions $\left(26 \pm 2^{\circ} \mathrm{C} ; 75 \pm 3 \% \mathrm{RH}\right.$; and $12 \mathrm{~L}: 12 \mathrm{D}$ photoperiod) and its immature stages are described. Egg development is divided into four stages, of which $\mathrm{S} 1$ took the longest time (accounting for $11.70 \%$ of total developmental time); $90 \%$ of the eggs that completed S2, hatched. Nymphal instars can be distinguished by body size, colour and other morphological features. Total developmental period of immature stages was approximately $50 \mathrm{~d}$, with the averages of the five stadia $5.18,4.33$, $5.28,10.41$ and 8.5 days, respectively. Using this rearing technique, it is possible to rear $A$. liuensis throughout the year, which will facilitate further ecological, behavioural and molecular studies and the development of ways of controlling this insect in the field.
\end{abstract}

\section{INTRODUCTION}

Cercopidae (Hemiptera: Cicadomorpha: Cercopoidea) is the largest family of xylem-sap sucking insects, with about 1500 described species in 150 genera recorded in the temperate, tropical and subtropical regions of the world (Carvalho \& Webb, 2005; Soulier-Perkins \& Kunz, 2012). Most nymphs of Cercopidae are commonly known as spittlebugs, due to the foam they produce (Paladini \& Cavichioli, 2015) and the adults feed on leaves or stems of a wide variety of plants (Vinton et al., 2006).

The genus Abidama, which currently includes eight species (Zhou \& Wu, 1987), was established by Distant (1908) for Sphenorhina producta Walker. Abidama liuensis (Metcalf, 1961) that was placed in this genus by Distant (1908) is an important pest of rice and maize, and was first reported in the southwest of Anhui province in China in 1988. In recent years, it has also been reported from Zhejiang, Fujian, Guizhou, Hubei and Henan provinces (Zhou \& Wu, 1987). During almost the whole of its development on rice, this insect ingests essential nutrients by sucking the stems, which can result in serious damage (up to $80 \%$ reduction in production) (Guan \& Zuo, 1991).
There are few studies on the occurrence and control of $A$. liuensis due to the lack of information on its biology and morphology. With the development of rearing techniques, other cercopids have been successfully reared in the laboratory (Fewkes \& Demidecki-Demidowicz, 1971; McWilliams \& Cook, 1975; Lapointe et al., 1989). Development of technique for rearing A. liuensis in the laboratory would greatly facilitate future biological and molecular studies on this species. There is some knowledge of the biology of cercopids, but the immature stages of most species have not been described (Peck et al., 2004; Vinton et al., 2006; Garcia et al., 2007; Wilson \& Mühlethaler, 2010; Chen \& Liang, 2012). In addition to those of the cercopids Lepyronia quadrangularis (Say, 1825) (Doering, 1923), Callitettix versicolor (Fabricius, 1794) (Chen \& Liang, 2012), Notozulia entreriana (Berg, 1879) (Foieri et al., 2016b) and Deois mourei (Cavichioli \& Sakakibara, 1993) (Foieri et al., 2016a), the immature stages of several species of Auchenorrhyncha, in different families, including Cicadidae, Membracidae, Achilidae, Delphacidae, and Fulgoridae, are described (Wilson \& Mcpherson, 1981; Wilson, 1983; Wilson \& Wheeler, 1992; Maccagnan \& Martinelli,

\footnotetext{
* Corresponding author; e-mail: liangap@ioz.ac.cn
} 

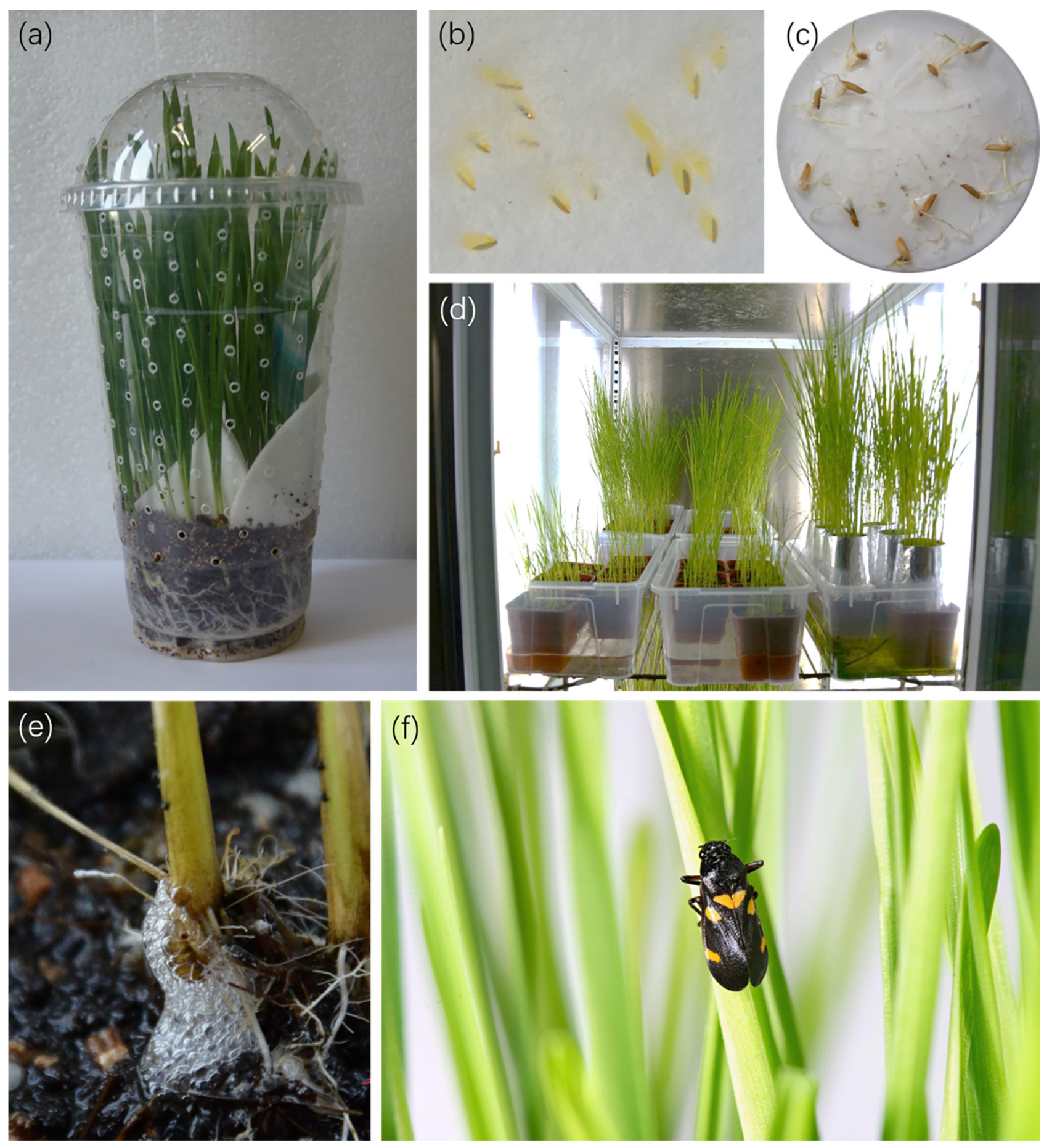

Fig. 1. Photographs of the apparatus used for the laboratory rearing of Abidama liuensis. (a) plastic cup used to rear adults and for collecting eggs; (b) eggs inserted into moistened filter paper; (c) nymphs reared in Petri dish; (d) rice cultivated in an environmental chamber for rearing nymphs; (e) nymph enclosed in foam; (f) adult on leaf of wheat seedling.

2004; Linares et al., 2010). Suitable temperature and high relative humidity are most important for the continuous production of spittlebugs under artificial conditions. Further important provisions are favourable conditions for the development of nymphs (abundance of surface roots, high humidity and darkness) and collecting eggs efficiently and conveniently (Lapointe et al., 1989; Peck et al., 2004; Chen \& Liang, 2012).
In the current study, techniques for rearing the immature stages of A. liuensis in the laboratory are described and illustrated.

\section{MATERIAL AND METHODS}

\section{Laboratory rearing}

A colony of $A$. liuensis was established in the laboratory from individuals collected from rice (Oryza sativa L.) growing in Wugang City, Henan province, China, in mid-autumn 2016 and summer 2019. Two male and two female adults were reared in plastic 
Table 1. Rice $1 / 2$ Kimura B nutrient solution formula.

\begin{tabular}{lccc}
\hline Solution & Ingredients & $\begin{array}{c}\text { Stock concentration } \\
(\mathrm{mol} / \mathrm{L})\end{array}$ & $\begin{array}{c}1 / 2 \mathrm{Kimura} \\
\text { fluid }(\mathrm{ml} / \mathrm{L})\end{array}$ \\
\hline Stock1 & $\mathrm{KH}_{2} \mathrm{PO}_{4}$ & 0.182 & 0.5 \\
\hline Stock2 & $\mathrm{MgSO}_{4} \cdot 7 \mathrm{H}_{2} \mathrm{O}$ & 0.547 & 0.5 \\
& $\left(\mathrm{NH}_{4}\right)_{2} \mathrm{SO}_{4}$ & 0.365 & 0.5 \\
Stock3 & $\mathrm{KNO}_{3}$ & 0.183 & \\
& $\mathrm{Ca}\left(\mathrm{NO}_{3}\right)_{2} \cdot 4 \mathrm{H}_{2} \mathrm{O}$ & 0.366 & \\
& $\mathrm{H}_{3} \mathrm{BO}_{3}$ & 0.030 & 0.1 \\
Stock4 & $\mathrm{MnCl}_{2} \cdot 4 \mathrm{H}_{2} \mathrm{O}$ & 0.005 & \\
& $\left(\mathrm{NH}_{4}\right)_{6} \mathrm{Mo}_{7} \mathrm{O}_{24} \cdot 4 \mathrm{H}_{2} \mathrm{O}$ & 0.010 & 0.1 \\
\hline $\mathrm{Zu}$ & $\mathrm{ZSO}_{4} \cdot 7 \mathrm{H}_{2} \mathrm{O}$ & 0.004 & 0.2 \\
\hline Fe & $\mathrm{CuSO}_{4} \cdot 5 \mathrm{H}_{2} \mathrm{O}$ & 0.002 & \\
\hline
\end{tabular}

cups $(10 \times 8 \times 8 \mathrm{~cm})$ the surfaces of which were perforated with $1 \mathrm{~mm}$ diameter holes. Fresh wheat (Triticum aestivum L.) in the cups was changed every 3-4 days and female adults mated and laid eggs on moistened filter paper (Fig. 1a).

Eggs laid on the filter papers were gently transferred onto moistened filter paper in a Petri dish (9 $\mathrm{cm}$ diameter) using soft tweezers (Fig. 1b), and kept in an environmental chamber at 25 $\pm 1{ }^{\circ} \mathrm{C}$ in the dark and at $80 \%$ relative humidity. The eggs were examined daily in order to predict when they would hatch. Those eggs that were about-to-hatch were removed and placed in separate Petri dishes in a vertical position on a moistened filter paper along with three to five sprouting rice seeds (Fig. 1c).

The nymphs were fed rice seedlings cultivated in the following way: (1) seeds were soaked in water at $28^{\circ} \mathrm{C}$ for $48 \mathrm{~h}$, which was changed every $12 \mathrm{~h} ;(2)$ the soaked seeds were packed into a piece of wet gauze at $28^{\circ} \mathrm{C}$ for about $12 \mathrm{~h}$; (3) a plastic pot $(10 \times 8 \times 8$ $\mathrm{cm}$ ) was filled with soil (home gardening nutritive soil : black soil $:$ vermiculite $=1: 1: 1), 15-20$ sprouted seeds were placed on the soil and covered with a layer of vermiculite or soil; (4) six plastic pots with seeds were placed in a plastic box $(35 \times 20 \times 13 \mathrm{~cm})$ and covered with aluminium foil to keep them warm, wet and dark, and kept in an environmental chamber at $26 \pm 2{ }^{\circ} \mathrm{C}$ under a $12 \mathrm{~L}$ : $12 \mathrm{D}$ photoperiod and $75 \pm 3 \%$ relative humidity (RH); (5) and when after 3 days the rice seedlings were about $4-5 \mathrm{~cm}$ tall the aluminium foil was removed; (6) when the rice seedlings were $20 \mathrm{~cm}$ tall, a bottomless, aluminium foil covered plastic cup was placed on the soil to provide a dark environment for the nymphs (Fig. 1d). Pots were watered every day by pouring $1 / 2$ Kimura B nutrient solution (Table 1) into the plastic box in which each pot was standing. The water level in the box was kept below the soil surface in order to prevent the nymphs from drowning.

The nymphs were placed on the roots of $10 \mathrm{~cm}$ tall rice seedlings about two weeks later (Fig. 1e). To determine the duration of nymphal development, the pots were examined daily, moults recorded, and ten nymphs were grouped in each pot based on their moulting date to determine stadia. Since nymphs of $\mathrm{A}$. liuensis are encased in foam it was difficult to observe when they moulted and determine their stage of development. Head width (HW, the maximum distance between compound eyes) of successive instars $(\mathrm{N}=207)$ were measured, and frequency distribution of head widths (group interval $=0.05 \mathrm{~mm}$ ) was used to determine the number of immature stages (Hutchinson \& Tongring, 1984; Sehnal, 1985; Dyar, 2008; Richards, 2010).

Nymphs and adults were all kept in an artificial climate chamber (GP-01, Huangshi Hengfeng Medical Instrument Co., Ltd., Hubei, China) at $26 \pm 2{ }^{\circ} \mathrm{C}$ under a $12 \mathrm{~L}: 12 \mathrm{D}$ photoperiod and 75 $\pm 3 \%$ relative humidity $(\mathrm{RH})$.

\section{Morphological studies}

All descriptions and illustrations of the egg and each nymphal instar were based on laboratory reared individuals. Specimens were anesthetized by freezing for ten minutes, fixed in $0.65 \%$ $\mathrm{NaCl}$, and observed under a Zeiss (Stemi SV 11) optical stereomicroscope (Carl Zeiss, Göttingen, Germany). Photographs of instars at different focal distances were taken with a Nikon D7000 camera attached to the stereomicroscope and combined into a fully focused image by Helicon Focus v6.7.1 Pro. Measurements were made using an ocular micrometre.

The fifth instar was described in detail and only major differences were highlighted in the descriptions of earlier instars. Colour was described based on examination of living specimens that had been frozen for two minutes. The measurements are averages for 30 specimens of each stage and are given in millimetres. Egg measurements were taken at the red eye stage of development.

Dimensions are expressed as body length (L) from apex of vertex to end of abdomen; width (W), across the widest part of metathorax; and head width (HW), the maximum distance between compound eyes. Measurements are given as mean \pm SD. Data were analysed with the SPSS Statistics v13.0 for Windows.

\section{RESULTS}

\section{Laboratory rearing}

When hatching, first instar nymphs opened the operculum from inside and emerged through the split. After settling on the roots of rice seedlings, they began to feed and enclose themselves in foam (Fig. 1c). During all immature stages, nymphs stayed and fed on the roots of rice seedlings. At the end of the fifth stage, the nymphs climbed up the rice stem and enclosed themselves in foam prior to adult emergence (Fig. 1e).

The statistical analysis of 210 randomly selected eggs showed that the average duration from laying to hatching was 16.29 days (Table 2), which is $32.59 \%$ of the total de-

Table 2. Duration of development (in days) of eggs and immature stages of Abidama liuensis under controlled laboratory conditions.

\begin{tabular}{|c|c|c|c|c|c|c|}
\hline Stage & $\begin{array}{c}\text { Duration (mean } \pm \text { SD) } \\
\text { (Day) }\end{array}$ & $\begin{array}{c}\text { Range } \\
\text { (Day) }\end{array}$ & $\begin{array}{l}\text { Cumulative mean age } \\
\text { (Day) }\end{array}$ & $\begin{array}{l}\text { No. entering } \\
\text { stage }\end{array}$ & $\begin{array}{l}\text { No. completing } \\
\text { stage }\end{array}$ & $\begin{array}{c}\text { Percentage } \\
\text { survival }\end{array}$ \\
\hline $\mathrm{S} 1$ & $5.85 \pm 1.47$ & $1-19$ & 5.85 & 210 & 202 & $96.19 \%$ \\
\hline S2 & $2.21 \pm 1.02$ & $1-7$ & 8.06 & 202 & 182 & $90.09 \%$ \\
\hline S3 & $3.98 \pm 0.83$ & $2-8$ & 12.04 & 182 & 139 & $76.37 \%$ \\
\hline S4 & $4.25 \pm 0.81$ & $3-6$ & 16.29 & 139 & 113 & $81.29 \%$ \\
\hline 1 & $5.18 \pm 1.98$ & $2-10$ & 21.47 & 113 & 93 & $82.30 \%$ \\
\hline II & $4.33 \pm 1.99$ & $1-9$ & 25.80 & 93 & 92 & $98.92 \%$ \\
\hline III & $5.28 \pm 1.48$ & $2-8$ & 31.08 & 92 & 86 & $93.48 \%$ \\
\hline IV & $10.41 \pm 2.51$ & $3-16$ & 41.49 & 86 & 73 & $84.88 \%$ \\
\hline V & $8.50 \pm 2.47$ & $2-15$ & 49.99 & 73 & 57 & $78.08 \%$ \\
\hline
\end{tabular}




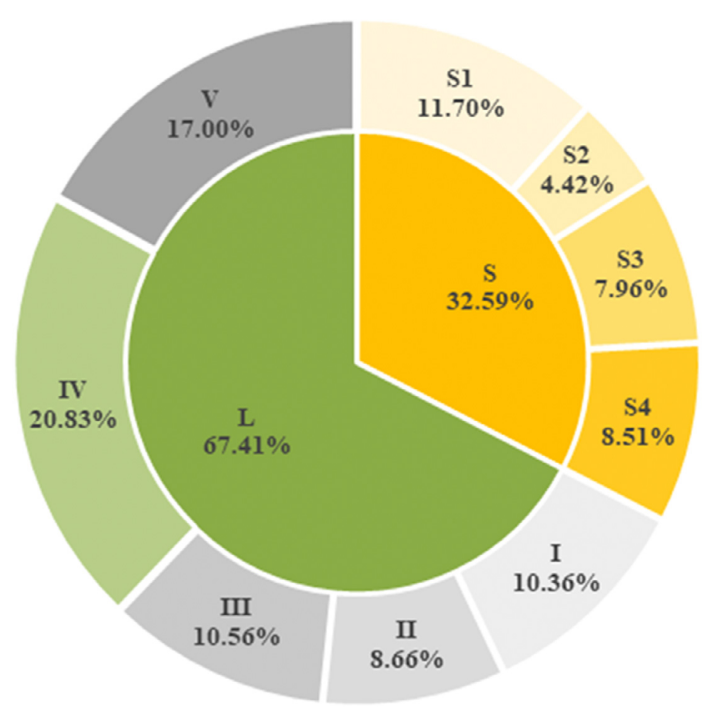

Fig. 2. Percentage of the total developmental time taken by each immature stage of $A$. liunesis under controlled laboratory conditions. S1-S4 indicate the four development stages of eggs. I-V indicate five immature stages of nymphs.

velopmental period (Fig. 2). Of the four stages, S1 was the longest and $90 \%$ of the eggs that survived S2 successfully hatched, which indicates that $\mathrm{S} 2$ is the most critical stage in the development of eggs. Of the 210 eggs, 113 hatched and 57 nymphs reached the adult stage. The total immature developmental period was approximately $50 \mathrm{~d}$, in which the first, second, third, fourth and fifth stadia averaged 5.18, $4.33,5.28,10.41$ and 8.5 days, respectively.

The hatchability of a total of 605 eggs laid by seven females was recorded (Fig. 3). On the 12th day after laying, nymphs began to emerge through a split in the eggs with $68.1 \%$ of the eggs hatching on the 16 th, 17 th and 18 th day. The peak in hatching (170) occurred on the 17 th day, when $28.1 \%$ of the eggs hatched.

Over a period of approximately one year, more than 980 eggs were observed. In each cycle of emergence, $29.8 \%$ of the adults emerged in the third week after the first adult emerged (Fig. 4). During the whole period of adult emergence, the ratio of female to male increased gradually and peaked on the 19th day.

Under laboratory conditions, the life span of the adults was $16.71 \pm 10.40 \mathrm{~d}$ for females and $15.39 \pm 9.89 \mathrm{~d}$ for males. Generally, males mated as soon as they emerged, whereas only three-day-old females were mature and observed mating. The average number of eggs laid per female (age $\geq 10 \mathrm{~d}, \mathrm{~N}=98$ ) was $76.94 \pm 45.80$ and the peak of oviposition occurred 9 days after emergence.

The frequency distribution of the head widths (group interval $=0.05 \mathrm{~mm})$ of the successive instars $(\mathrm{N}=207)$ revealed 5 obvious peaks, indicating five nymphal instars. The head width of instars $1-5$ were $0.30 \pm 0.02 \mathrm{~mm}, 0.45$ $\pm 0.04 \mathrm{~mm}, 0.70 \pm 0.08 \mathrm{~mm}, 1.05 \pm 0.04 \mathrm{~mm}$ and 1.41 $\pm 0.14 \mathrm{~mm}$, respectively. The widths of head in the successive instars followed a regular geometrical progression (Hutchinson \& Tongring, 1984; Sehnal, 1985; Dyar, 2008; Richards, 2010), according to Dyar's law with an average increase per instar of 1.46 .

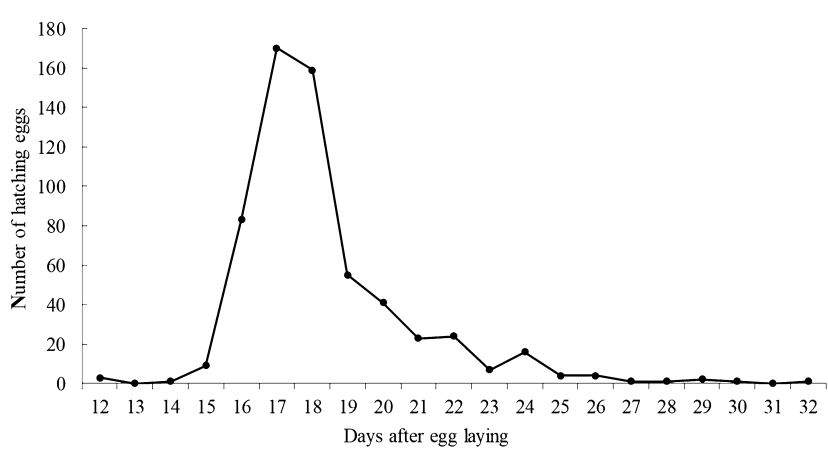

Fig. 3. Number of eggs in a cohort laid by $A$. liunesis that hatched on consecutive days.

\section{Description of the immature stages}

Fifth instar (Figs $5 \mathrm{f}$ and g) Length (L): $4.75 \pm 1.07 \mathrm{~mm}$; width (W): $2.40 \pm 0.22 \mathrm{~mm}$.

Body brown, spindle-shaped, widest across abdominal segment 3 .

Vertex dark brown, convexly curved (female) or slightly pointed anteriorly (male) (Figs $5 \mathrm{~h}$ and i). Frons brown, in ventral view, with dark grey longitudinal median line, convex, with a straight inferior margin (Fig. 5g). Clypeus brown, in frontal view, nearly triangular, flattened, narrowing apically (Fig. 5j). Rostrum three-segmented, nearly cylindrical, half of segment 1 hidden by clypeus, segment 2 $7 / 9$ of the length of segment 3 , segment 3 with dark brown apex, tip extending to metacoxae (Fig. 5j). Antennae 3-segmented, pale brown, translucent, setiform, inserted at the junction of frons, vertex and gena; scape brown, cylindrical with narrow base, broadening apically; pedicel brown, cylindrical, slightly thinner than scape; flagellum with seven flagellomeres, 1/2 diameter and twice the length of pedicel, translucent, and bristle-like extension distally, the first four flagellomeres with apical single trichoid sensilla (Fig. 51). Compound eyes reddish brown, subcylindrical; 2 ocelli on vertex, white with red edge, circular, between compound eyes, near median line.

Pronotum sub rectangular, straight anterior margin following posterior border of head, posterior margin curved anteriorly near middorsal line. Mesonotum $4 / 3 \times$ length of pronotum, anterior margin straight, posterior curved posteriorly near middorsal line; mesonotal wing pads lobate, extending to posterior margin of metanotal wing pads. Metanotum 1/4 $\times$ length of mesonotum, narrow, sub rectangular, anterior and posterior margins straight, metanotal wing pads extending to anterior margin of abdominal segment 3. Legs with pro-, meso- and metacoxae elongate and directed posteromedially; lengths similar. Trochanters short and subcylindrical. Femora elongate, subcylindrical, with translucent short setae, length of metafemora similar to profemora, longer than mesofemora, but thicker than the latter two. Tibiae subcylindrical, with reddish brown setae on the shaft, pro- and mesotibiae equal in length to femora, metatibiae ca. $4 / 5 \times$ length of femora, slightly thinner than femora (Fig. 5k); with two rows of spines (8 long and 8 short on meso- and metatibiae, 7 long and 7 short on protibiae). Pro- and mesotarsi with two tarsomeres, tarsomere 1 


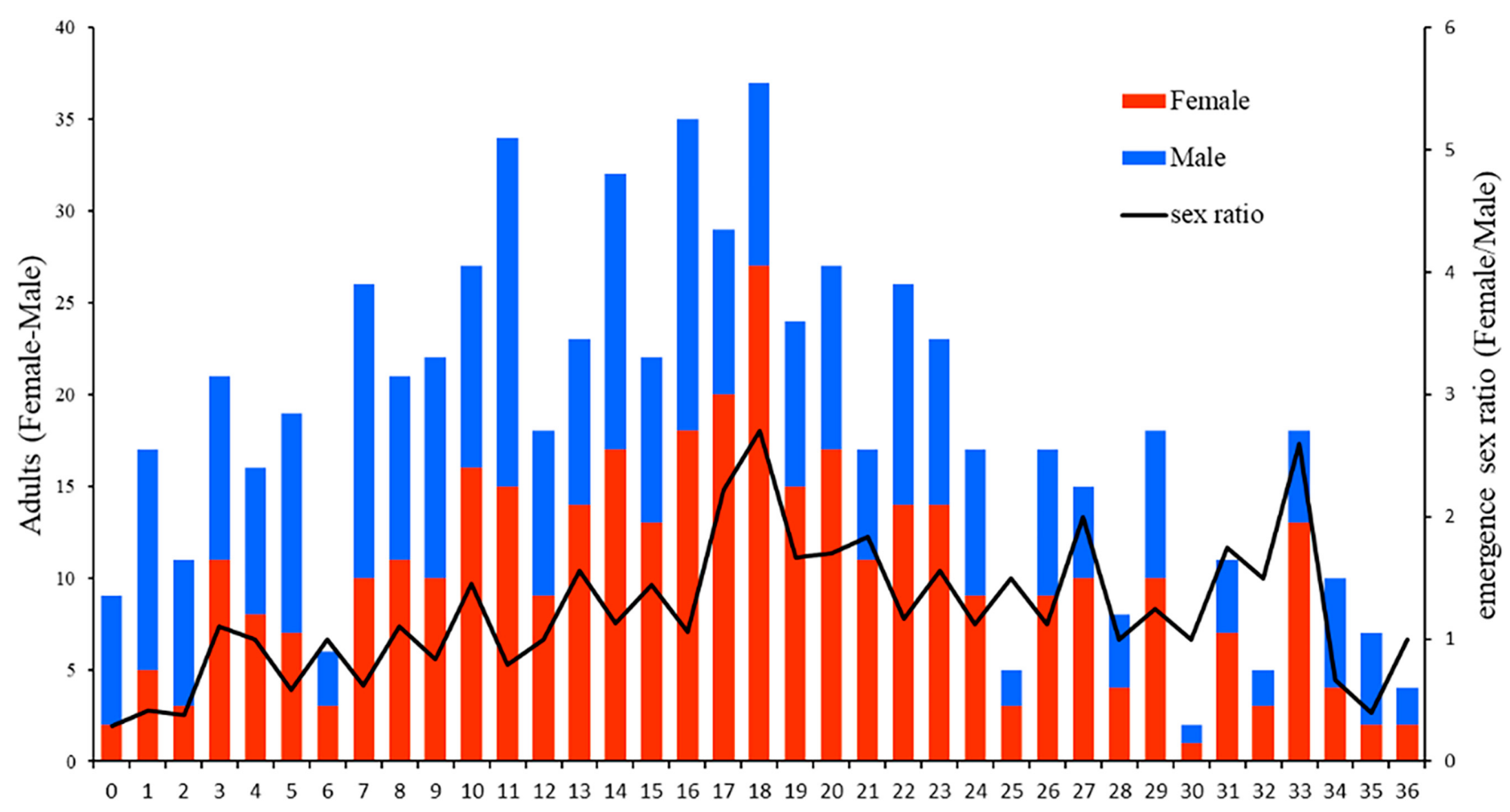

Days after first adult emergence

Fig. 4. The numbers of females and males in a cohort that emerged on consecutive days (left) and ratio of the two sexes (female/male) (right) in a mass-reared colony of $A$. liuensis.

wedge-shaped, with ca. 15 apical spines on plantar surface; tarsomere 2 subcylindrical, ca. $2 \times$ length of tarsomere 1 . Metatarsi with three tarsomeres, tarsomere 1 subcylindrical, with ca. 18 apical spines on plantar surface; tarsomere 2 subcylindrical, $1 / 2 \times$ length of tarsomere 1 , with ca. 7 reddish brown-tipped apical spines on plantar surface; tarsomere 3 subcylindrical, $1 / 2 \times$ length of tarsomere 1 . All legs with a pair of apical claws and median pulvillus.

Abdomen nine-segmented. Tergites 1-3 brown, sub rectangular, tergite $11 / 2 \times$ length and width of tergites 2 and 3; tergites 4-7 dark brown, sub trapezoidal, lengths similar to each other, the latter $2 / 3 \times$ width of the former; tergite 8 cylindrical, length equal to tergite $7,1 / 2 \times$ diameter of tergite 7 ; tergite 9 sub cylindrical, $2 \times$ length of tergite 8 and width similar to tergite 8 .

Fourth instar (Fig. 5e) Length: $3.30 \pm 0.28 \mathrm{~mm}$; width: $1.14 \pm 0.20 \mathrm{~mm}$.

Body sub cylindrical, head and thorax greyish-brown, abdomen reddish orange. White middorsal line extending from $1 / 2$ of vertex to posterior end of metanotum.

Frons greyish-brown, sub cylindrical. Compound eyes bright red, semi-circular (the straight edge parallel to thoracic nota, the curved edge irregular). Ocelli light yellow, dot-like. Antennal flagellum with 7 flagellomeres. Rostrum extending to between meso- and metacoxae.

Thoracic nota greyish brown. Pronotum ca. $1.5 \times$ length of mesonotum. Metanotum narrow, $1 / 4 \times$ length of mesonotum. Mesonotal wing pads shorter, $4 / 5 \times$ length of metanotal wing pads, metanotal wing pads extending to posterior margin of first abdominal segment. Femora and tibiae with light brown setae; pro-, meso- and metatibiae each with a row of 7 apical spines on plantar surface. Tarsi two-segmented.

Abdomen with 9 tergites. Tergites 1-7 orange, tergites 8-9 light brown.

Third instar (Fig. 5d) Length: $2.34 \pm 0.36 \mathrm{~mm}$; width: $0.87 \pm 0.06 \mathrm{~mm}$.

Body spindle shaped, head and thorax pale brown, abdomen orange, integument translucent. White middorsal line extending from anterior margin of pronotum to posterior border of metanotum.

Vertex and frons pale brown, Frons bulbous, sub oval. Compound eyes blood red, apricot shaped, with irregular edge. The number of ommatidia less than in the fourth instar and the gap between the third and fourth greater than between the fourth and fifth. Ocelli absent. Flagellum with 7 flagellomeres. Rostrum extending to between metacoxae.

Thoracic nota brownish-yellow. Pronotum $1.4 \times$ times length of mesonotum; metanotum narrow, $1 / 5 \times$ length of mesonotum. Femora and tibiae with light yellowish setae; a row of 7 brown-pointed spines on posterior margin of tibiae; several translucent setae on shaft of tibiae. Tarsi 2-segmented.

Abdomen dorsally orange and ventrally white, 8-segmented, each segment with orange stripe, orange marks on both sides expanded into two intersecting rings.

Second instar (Fig. 5c) Length: $1.95 \pm 0.45 \mathrm{~mm}$; width: $0.57 \pm 0.06 \mathrm{~mm}$.

Body subcylindrical, head, thorax and abdomen pale yellow, integument translucent.

Vertex light yellow. Frons slightly bulbous. Eyes light red. No ocelli. Scape wide, antennal flagellum with four 

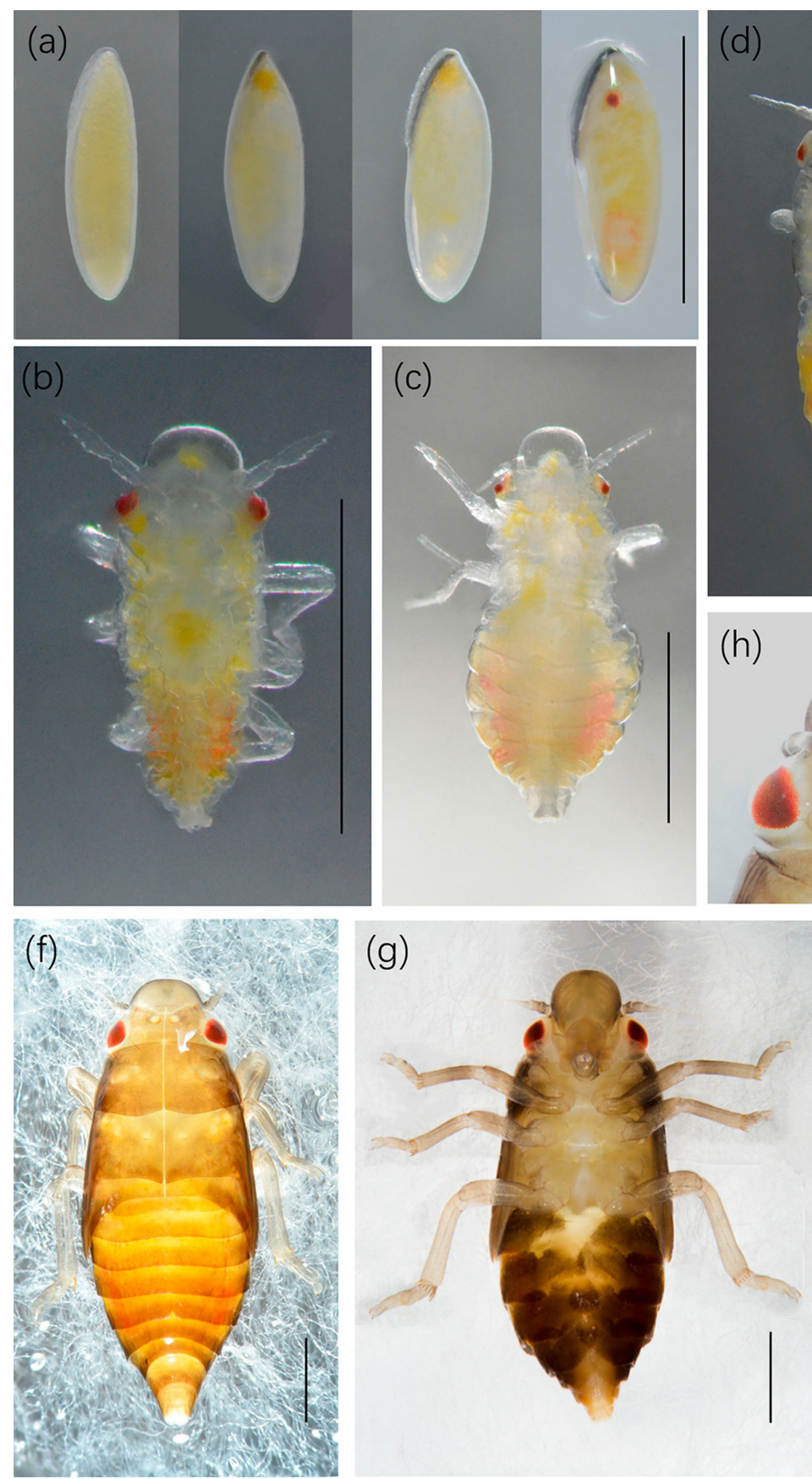
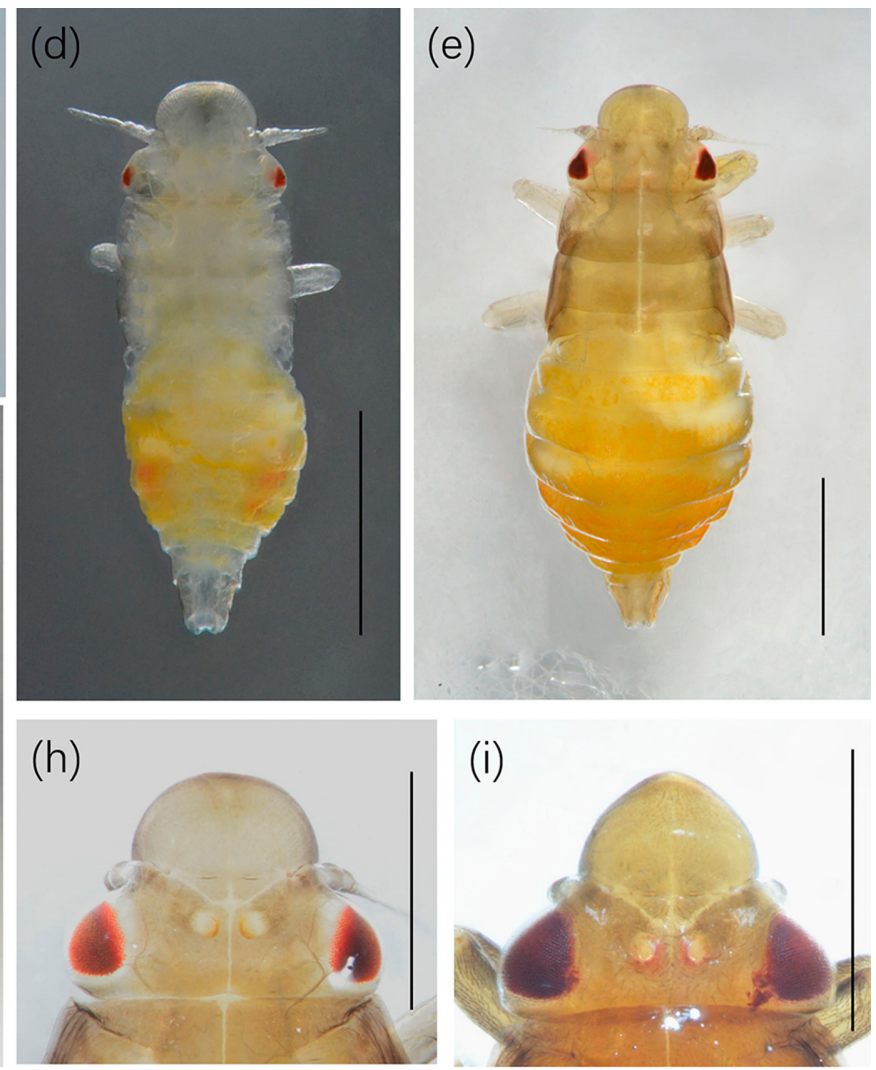

(i)
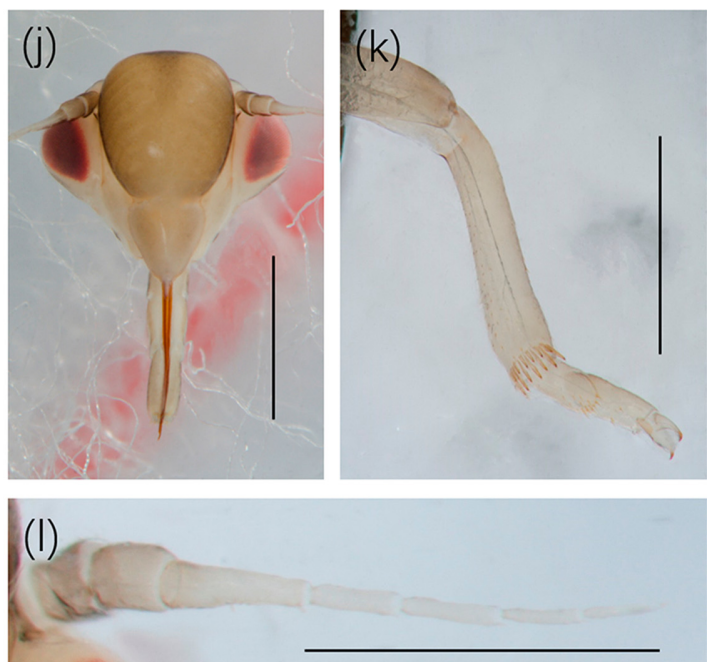

Fig. 5. Photographs of the eggs and nymphs of $A$. liuensis. (a) four stages in the development of eggs; (b) first instar nymph; (c) second instar nymph; (d) third instar nymph; (e) fourth instar nymph; (f) dorsal view of fifth female instar; (g) ventral view of fifth female instar; (h) head of fifth female instar; (i) head of fifth male instar; (j) frontal view of head of fifth female instar; (I) antennae of fifth female instar; ( $k$ ) metatibiae and metatarsi of fifth female instar. Vertical bar $=1.0 \mathrm{~mm}(\mathrm{a}-\mathrm{k})$ or $0.5 \mathrm{~mm}(\mathrm{l})$.

flagellomeres. Rostrum extending ventrally to posterior margin of metathorax.

Thoracic nota small, with discontinuous yellow stripes. Wing pads absent. No setae on protibiae, several translucent setae on plantar surface of meso- and metatibiae. Tibiae each with an apical row of 7 spines on plantar surface.

Abdomen yellow, nearly spherical, segmentation difficult to discern, more deeply reddish orange ring-shaped masses symmetrically on both sides, $3.5 \times$ length of thorax.

First instar (Fig. 5b) Length: $1.15 \pm 0.52 \mathrm{~mm}$; width: $0.41 \pm 0.06 \mathrm{~mm}$.
Body pale yellow, translucent, sub ovoid, ventral part of abdomen reddish orange. Mid-dorsal line unclear.

Vertex white, translucent, slightly square, flattened. Antennae three-segmented; length of scape and pedicel subequal, $3 \times$ length of the first and second flagellomeres; flagellum with 4 flagellomeres, length of the basal two flagellomeres $2 \times$ length of the distal two flagellomeres. Ocelli absent.

Thorax white, translucent, weakly sclerotized but segmented and difficult to see. Few setae on tibiae and tarsi. A row of 5 spines on apex of femora. 
Abdomen pale yellow, subcylindrical, reddish orange ring-shaped masses symmetrically on both sides, without apparent segmentation, $2 \times$ length of thorax.

Egg (Fig. 5a) Length: $0.92 \pm 0.02 \mathrm{~mm}$; width: $0.32 \pm$ $0.01 \mathrm{~mm}$.

Eggs with smooth chorion, were generally inserted singly into filter paper (Fig. 1b). The development of the egg can be divided into four stages (S1, S2, S3 and S4) (Fig. 5a). The newly deposited eggs were light yellow; the anterior aspect of the egg bore an oval operculum, which was closed when laid (S1) and gradually opened about 1 week before hatching, during period (S2-S4) the operculum colour changed from light grey to black. Moreover, the cephalic end of the egg near the operculum was pale red in $\mathrm{S} 2$ and moved slowly to an abdominal position in S4. In $\mathrm{S} 4$, there are red eyespots on both sides of the egg near the anterior $1 / 4$.

\section{DISCUSSION}

Low viability of laboratory reared nymphs is reported by Garcia et al. (2007), with only $18.9 \%$ of the eggs of $\mathrm{Ae}$ neolamia varia developing into adults (Peck et al., 2004). In addition, only nine of more than 100 randomly selected eggs of another spittlebug, $C$. versicolor, reached the adult stage when reared in a laboratory (Chen \& Liang, 2012). However, in the current study, percentage survival was nearly $30 \%$ and the percentage moulting to the next stage was no less than $76 \%$. The quality of the rice may have affected the development of nymphs, in terms of lengthening the duration of each stage and low viability, by not providing suitable nutrition for their development (Sforza et al., 1999). Therefore, by providing first instars nymphs with high quality roots of rice could improve their survival under the same conditions of light and humidity.

A major challenge is the provision of an abundance of high-quality rice roots for rearing the nymphs. Although a relatively high-water table and darkness is beneficial for the development of rice roots, the resultant high humidity results in the growth of mildew, which adversely affects the nymphs. Another problem with such a rearing environment is that it can result in outbreaks of fungal entomopathogens and other insect pests. Improving ventilation, disinfecting before planting (sterilizing the pots and soil at $121^{\circ} \mathrm{C}$ for $15 \mathrm{~min}$, and soaking rice seeds in $2 \%$ sodium hypochlorite) and reducing the amount of rice (10-20 seeds) growing in each environmental chamber may help address these problems. Interestingly, mildew growth declined a few days after the nymphs began feeding on the rice roots, indicating that there may be antifungal substances in the foam produced by the nymphs.

The S1 developmental period of the eggs is much longer than other stages (Table 2 and Fig. 2), and most eggs that were viable at the end stage $\mathrm{S} 2$ subsequently hatched. Diapause in the egg stage is reported in many spittlebugs, such as Deois flavopicta (Stål, 1854) (Sujii et al., 2001), Mahanarva spectabilis (Distant, 1909) (Auad et al., 2011) and C. versicolor (Chen \& Liang, 2012). Sujii et al. (2001) increased the synchronization of hatching and reduced the duration of the egg stage in D. flavopicta by lowering the overnight temperature. In addition, eggs of $C$. versicolor reared in our laboratory hatched within 80 days when kept at a low temperature $\left(5^{\circ} \mathrm{C}, 40\right.$ days $)$, but take up to 200 days under controlled laboratory conditions (Zhang \& Liang, 2018). However, there was no obvious diapause in the development of the eggs of A. liuensis and it is most likely that those that failed to hatch did so because of the poor quality of the females that laid them.

In this study, at the end of 5th stage, the body of males was covered by black setae, which was not observed in females. The causes of morphological differences between sexes need further study and molecular biological verification.

The absence of ocelli in the early nymphal stages might be an adaptation to a radicicolous life and is considered as a synapomorphy of planthoppers (Cixiidae) (Suchov \& Vovk, 1948; Hoch, 1994; Bourgoin, 1997), scarabs (Scarabaeoidae) (Eilers et al., 2012) and other cercopids (Chen \& Liang, 2012). Compared to the 1st-3rd instar nymphs, which had translucent bodies, 4th and 5th instar nymphs have larger and brown bodies and are more easily found by predators. In this study it was noticeable that the older nymphs were more sensitive to moving objects. Whether this is related to the presence of ocelli needs to be verified experimentally.

ACKNOWLEDGEMENTS. This study was supported by The National Natural Science Foundation of China (Grant No. 31872279) and The Biodiversity Survey and Assessment Project of the Ministry of Ecology and Environment, China (Grant No. 2019HJ2096001006).

\section{REFERENCES}

Auad A.M., Simões A.D., Leite M.V., Da Silva S.E.B., dos SanTOS D.R. \& Monteiro P.H. 2011: Seasonal dynamics of egg diapause in Mahanarva spectabilis (Distant, 1909) (Hemiptera: Cercopidae) on elephant grass. - Arq. Inst. Biol. (Sao Paulo) 78: $325-330$.

BouRgoIn T. 1997: Habitat and ant-attendance in Hemiptera: a phylogenetic test with emphasis on trophobiosis in Fulgoromorpha. In Grancolas P. (ed.): The Origin of Biodiversity in Insects: Phylogenetic Tests of Evolutionary Scenarios. French National Museum of Natural History, Paris, pp. 109-124.

Carvalho G.S. \& Webb M.D. 2005: Cercopid Spittle Bugs of the New World (Hemiptera, Auchenorrhyncha, Cercopidae). Pensoft, Sofia, $271 \mathrm{pp}$.

CHen X. \& Liang A.P. 2012: Laboratory rearing of Callitettix versicolor (Hemiptera: Cicadomorpha: Cercopidae), with descriptions of the immature stages. - Ann. Entomol. Soc. Am. 105: 664-670.

Doering K.C. 1923: Biology and Morphology of Lepyronia quadrangularis (Say), (Homoptera, Cercopidae). MSc. thesis, University of Kansas, pp. 49-55.

DYAR H.G. 2008: The number of molts of Lepidopterous larvae. - Psyche 5: 420-422.

Eilers E.J., Talarico G., Hansson B.S., Hilker M. \& Reinecke A. 2012: Sensing the underground-ultrastructure and function of sensory organs in root-feeding Melolontha melolontha $(\mathrm{Co}-$ leoptera: Scarabaeinae) larvae. - PLoS ONE 7: e41357, 20 pp. 
Fewkes D.W. \& Demidecki-Demidowicz M.R. 1971: Rearing technique for sugar cane froghopper nymphs (Homoptera: Cercopidae). — Ann. Entomol. Soc. Am. 64: 1471-1472.

Foieri A., Lenicov A.M.M.D.R. \& VirLa E.G. 2016a: Description of the immature stages and new host plant records of Deois (Deois) mourei (Berg) (Hemiptera: Cercopidae), a species newly recorded from Argentina and Paraguay. - Zootaxa 4161: 419-428.

FoIERI A., LENICOV A.M.M.D.R. \& VirLa E.G. 2016b: Descriptions of the immature stages and new host plant records of Notozulia entreriana (Berg) (Hemiptera: Cercopidae) pests of grasses in subtropical areas of the Americas. - Zootaxa 4103 : $54-62$.

Garcia J.F., Machado Botelho P.S. \& Postali Parra J.R. 2007: Laboratory rearing technique of Mahanarva fimbriolata (Stål) (Hemiptera: Cercopidae). — Sci. Agric. (Piracicaba) 64: 7376.

GuAN S.Q. \& Zuo Y.L. 1991: Preliminary study on the occurrence and control of Callitettix versicolor and Abidama liuensi. Plant Protection 17: 10-12 [in Chinese].

Guo K., Hao S.G., Sun O.J. \& Kang L. 2009: Differential responses to warming and increased precipitation among three contrasting grasshopper species. - Global Change Biol. 15: $2539-2548$.

Hосн H. 1994: Homoptera (Auchenorrhyncha, Fulgoroidea). In Juberthie C. \& Decu V. (eds): Encyclopedia Biospeleogica. Société de Biospéléologie, Moulis, Bucarest, pp. 313-325.

Hutchinson G.E. \& Tongring N. 1984: The possible adaptive significance of the Brooks-Dyar rule. $-J$. Theor. Biol. 106: 437-439.

Lapointe S.L., Sotelo G. \& Arango G. 1989: Improved technique for rearing spittlebugs (Homoptera: Cercopidae). $-J$. Econ. Entomol. 82: 1764-1766.

Linares M.A., Neder L.E. \& Dietrich C. 2010: Description of immature stages and life cycle of the treehopper, Guayaquila projecta. - J. Insect Sci. 10: 199, 9 pp.

Maccagnan D.H.B. \& Martinelli N.M. 2004: Description of the nymphs of Quesada gigas (Olivier) (Hemiptera: Cicadidae) associated with coffee plants. - Neotrop. Entomol. 33: 439-446.

McWilliams J.M. \& CooK J.M. 1975: Technique for rearing the twolined spittlebug. - J. Econ. Entomol. 68: 421-422.

Paladini A. \& Cavichioli R.R. 2015: A new genus and new species of spittlebug (Hemiptera: Cercopidae: Ischnorhininae) from Southern Brazil. — Zoologia (Curitiba) 32: 47-52.

Peck D.C., Morales A. \& Castro U. 2004: Alternative methods for rearing grass-feeding spittlebugs (Hemiptera: Cercopidae). - Neotrop. Entomol. 33: 307-314.

RichARDS O.W. 2010: The relation between measurements of successive instars of insects. - Proc. R. Entomol. Soc. Lond. 24: 8-10.
Sehnal F. 1985: Growth and life cycles. In Kerkut G.A. \& Gilbert L.I. (eds): Comprehensive Insect Physiology Biochemistry and Pharmacology, 2. Postembryonic Development. Pergamon, New York, pp. 1-86.

Sforza R., Bourgoin T., Wilson S.W. \& Boudon-Padieu E. 1999: Field observations, laboratory rearing and descriptions of immatures of the planthopper Hyalesthes obsoletus (Hemiptera: Cixiidae). — Eur. J. Entomol. 96: 409-418.

SмITH R.I.L. 1994: Vascular plants as bioindicators of regional warming in Antarctica. — Oecologia 99: 322-328.

Sotelo G., Lapointe S.L. \& Arango G.L. 1988: Nueva tecnica de cria del "salivazo de los pastos" en invernaero (Homoptera: Cercopidae). - Revta Colomb. Entomol. 14: 3-6.

Soulier-Perkins A. \& Kunz G. 2012: Revision of the malagassy endemic genus Amberana Distant (Hemiptera, Cercopidae) with description of one new genus. - Zootaxa 3156: 1-42.

Suchov K.C. \& Vovk A.M. 1948: Biology of the leafhoopper Hyalesthes obsoletus Sign., vector of the stolbur virus. Trudy Inst. Genet. 15: 193-202.

Suji E.R., Garcia M.A., Fontes E.M., Da Silva S.M. \& Meyer J.F. 2001: Soil temperature and diapause maintenance in eggs of the spittlebug, Deois flavopicta (Hemiptera: Cercopidae). Braz. J. Biol. 61: 605-613.

Thomas C.D. \& Lennon J.J. 1999: Birds extend their ranges northwards. - Nature 399: 213.

Vinton T., Carvalho G.S. \& Webb M.D. 2006: Cercopid spittle bugs of the New World (Hemiptera, Auchenorrhyncha, Cercopidae). - Ann. Entomol. Soc. Am. 99: 1259-1260.

WILSON S.W. 1983: Description of the fifth instar of Epiptera opaca (Homoptera: Fulgoroidea: Achilidae). — Gt. Lakes Entomol. 16: 1-3.

WILSON S.W. \& MCPHERSON J.E. 1981: Life history of Megamelus davisi with descriptions of immature stages. - Ann. Entomol. Soc. Am. 74: 345-350.

WiLson M.R. \& Mühlethaler R. 2010: The nymph of Zyginella pulchra Löw, 1885 (Hemiptera, Cicadellidae, Typhlocybinae). - Cicadina 11: 43-45.

WiLSON S.W. \& WheELER A.G.J. 1992: Host plant and descriptions of nymphs of the planthopper Rhabdocephala brunnea (Homoptera: Fulgoridae). - Ann. Entomol. Soc. Am. 85: 258-264.

Zhang D.J. 2018: Studies on the Mating Behavior and Vibrational Communication in the Rice Spittlebug Callitettix versicolor. Ph.D. thesis, Chinese Academy of Sciences, Beijing, 24 pp.

Zноu Y. \& Wu Z.L. 1987: Description of species in genus Abidama Distant (Homoptera: Cercopidae). - Entomotaxonomia 9: $21-25$.

Received October 14, 2020; revised and accepted February 22, 2021 Published online March 22, 2021 